\title{
Vitamin D Status and Usual Nutrient Intake of Filipino Children Aged 6-12 Years in Selected Areas in the Philippines: A 2018 National Nutrition Survey
}

\author{
Imelda Angeles-Agdeppa $(i)$ and Keith V. Tanda \\ Department of Science and Technology, Food and Nutrition Research Institute, Bicutan, Taguig, Philippines \\ Correspondence should be addressed to Imelda Angeles-Agdeppa; iangelesagdeppa@yahoo.com.ph
}

Received 9 July 2020; Revised 7 December 2020; Accepted 4 January 2021; Published 12 January 2021

Academic Editor: Elsa Lamy

Copyright ( 2021 Imelda Angeles-Agdeppa and Keith V. Tanda. This is an open access article distributed under the Creative Commons Attribution License, which permits unrestricted use, distribution, and reproduction in any medium, provided the original work is properly cited.

\begin{abstract}
Background. This study aimed to determine the prevalence of vitamin D deficiency, usual nutrient intake, and food sources of vitamin D of Filipino children aged 6-12 years in selected areas in the Philippines. Methods. The National Nutrition Survey (NNS) collected blood samples of children aged 6-12 years from selected study sites: Manila City and Quezon City in the National Capital Region (NCR); Cagayan Province and Baguio City in Luzon; Northern Samar and Siquijor in Visayas; and Butuan City and Sultan Kudarat in Mindanao. About 789 children aged 6-12 years participated in this study. Serum vitamin D was determined by electrochemiluminescence binding assay (ECLIA). Food intake data were collected using two-day nonconsecutive $24 \mathrm{~h}$ food recall. Usual nutrient intakes were estimated using Personal Computer Software for Intake Distribution Estimation (PC-SIDE) program. Results. The mean serum vitamin $\mathrm{D}$ of $25(\mathrm{OH}) \mathrm{D}$ was $72.7 \pm 0.67 \mu \mathrm{mol} / \mathrm{L}$. The overall prevalence of combined vitamin $\mathrm{D}$ deficiency $(<50 \mu \mathrm{mol} / \mathrm{L})$ and insufficiency $(51-74 \mu \mathrm{mol} / \mathrm{L})$ among children aged $6-12$ years was $60.6 \%$. Females had a higher prevalence of vitamin D insufficiency compared to males. NCR (57.9\%) had a higher deficiency compared to the other areas. The usual intake of vitamin $\mathrm{D}(2 \mu \mathrm{g} /$ day $)$ among children was below the adequate intake of $5 \mu \mathrm{g} /$ day. The main food sources of vitamin D are coming from fish (53\%), pork (19\%), and egg/egg dishes (16\%). Conclusion. This study revealed that there is a significantly high level of vitamin D insufficiency in children aged 6-12 years. Filipino females had higher prevalence of vitamin D deficiency and insufficiency compared to males. Among the areas, NCR has the highest prevalence of deficiency/insufficiency.
\end{abstract}

\section{Introduction}

Vitamin D, also known as the sunshine vitamin, is essential for the health and growth of bones. It helps the body to absorb calcium from the gut and regulates how much calcium and phosphorus gets stored in the bone. The vitamin D content of the human body is synthesized to 7-dehydrocholesterol (7DHC) by the exploit of ultraviolet B (UVB) irradiation from sunlight. It is converted to 25-hydroxyvitamin D $(25(\mathrm{OH}) \mathrm{D})$ in the liver by hydroxylase and then transported in the kidney forming 1 , 25-dihydroxyvitamin $\mathrm{D}\left(1,25(\mathrm{OH})_{2} \mathrm{D}\right)$ by other hydroxylation $[1,2]$.

Vitamin D and calcium are bone growth nutrients. In children, vitamin D deficiency can cause skeletal diseases such as nutritional rickets (NR), osteomalacia, and troubles in calcium homeostasis [3]. Also, the lack of vitamin D has been associated in mental health disorder and can cause neurohormonal effects on brain development and behaviour [4]. Globally, vitamin D deficiency is a major public problem in all age groups even in the countries with more sun exposure all year round [5]. The highest level of vitamin D serum values were observed in North America than in Europe or Middle East/Africa region. However, in the Asia region, children were found to have significantly lower vitamin D serum values than adults and elderly [6].

There are few foods that naturally contain vitamin D; hence, the amount of time in sunlight is important [7]. A previous study found out that sunlight exposure was thought to directly kill the tuberculosis bacteria [8]. There have been multiple cross-sectional studies associating lower vitamin D 
with increased infections. Individuals with less $<30 \mathrm{ng} / \mathrm{ml}$ of vitamin D levels were more likely to self-report a recent upper respiratory tract infection than those with sufficient levels, even after adjusting the variables of age, gender, season, body mass index, and race [9]. Just at this time of the coronavirus pandemic, numerous news reports considered vitamin $\mathrm{D}$ from sun exposure as one of the protective gear against the virus.

Because of the critical role of vitamin $\mathrm{D}$ both in growth of children and in immune response, this study aimed to determine the prevalence of vitamin D status, usual nutrient intake, and food sources of Vitamin D of Filipino children, aged 6-12 years in selected areas in the Philippines based on the 2018 National Nutrition Survey data (NNS 2018).

\section{Materials and Methods}

2.1. Study Population. The sampling frame of the 2018 National Nutrition Survey utilized the new 2013 master sample (MS) developed by the Philippine Statistics Authority (PSA). It is a two-stage cluster sampling design with the first stage being the selection of primary sampling units (PSUs) composed of barangays or Enumeration Areas (EAs) or a group of adjacent small barangays or EAs followed by the selection of secondary sampling units (SSUs) composed of housing units or households. Each PSU is composed of 100-400 households. The 2013 MS used provinces, highly urbanized cities (HUCs), and urban areas as its sampling domain. Finally, the NNS patterned the list of households from the 2015 Population Census.

Replicated sampling was employed in the selection of provinces and HUCs in order to gain efficiency in the generation of national-level estimates for a given year. This was carried out by grouping the provinces and HUCs with similar characteristics into "replicates." A replicate is composed of, at least, 5 provinces or HUCs. Compared from the previous surveys, the rolling survey termed as the Expanded National Nutrition Survey (ENNS) has 24 replicates (8 replicates per year) to achieve reliable domain-level estimates. It targets to cover 117 major sampling domains composed of 81 provinces, 33 HUCs (including 16 cities in the National Capital Region); and 3 other urban areas. A total of 40 provinces and HUCs were covered for the year 2018, while another 40 and 37 areas are expected to be surveyed for the subsequent years 2019 and 2020, respectively.

In all the ENNS components, an average of 1536 households were targeted except for the biochemical, dietary, and blood parameters of the clinical component. The target households covered for the two components were only half $(50 \%)$ or about 768 households. This is due to high cost of laboratory analyses for the biochemical component and a tedious data collection for the dietary survey.

Based from previous NNSs, the number of participating $6-12$-year-old children was on the average, $\pm 4,000$. Using the critical value of the normal distribution at $\alpha / 2$ (e.g., for a confidence level of $99 \%, \alpha$ is 0.01 and the critical value is 2.576) and the proportion of vitamin $\mathrm{D}$ deficiency based on the published literature of $40 \%$ with an acceptable sample error of 0.05 , the calculated sample size is 640 children.
All the 40 provinces covered in 2018 were clustered by region. Each region was then clustered into 3 island groups, namely, Luzon, Visayas, and Mindanao. From each Island group, 2 provinces were randomly selected as the study sites: These areas were Manila City and Quezon City in the National Capital Region (NCR) as highly urbanized cities; Cagayan Province is second largest region in terms of land area and lies in a large valley in northeastern Luzon; Baguio City is also a highly urbanized city in Luzon. The province of Northern Samar is bounded by the Pacific Ocean on the east; Siquijor is a coastal municipality in Visayas. Butuan City is a coastal, highly urbanized city, and Sultan Kudarat Province is a coastal area in Mindanao.

This study included children aged 6 to 12 years from the 8 study sites. There were 2782 children who participated in the dietary survey, and 789 children had blood samples for the analysis of serum vitamin D.

\subsection{Data Collection}

2.2.1. Dietary. Two-day nonconsecutive 24-h dietary recalls were conducted face-to-face with the parent or caregiver of each child. Trained registered nutritionists-dietitians carried out the interviews during household visits using structured questionnaires. To estimate the day-to-day variance component in energy and nutrient intake required for usual intake analysis, the first 24-h dietary recall was collected for all children and a second 24 -h dietary recall was repeated in $50 \%$ of randomly selected households on a nonconsecutive day. The second 24-h dietary recall was typically collected 2 days after the first $24-\mathrm{h}$ recall. The interviewer asked about all foods and beverages that the child consumed on the previous day. The amount of each food item or beverage was estimated using common household measurements such as cups, tablespoons, by size, or number of pieces. The information was then converted to grams using a portion to weight list for common foods compiled by the Department of Science and Technology-Food and Nutrition Research Institute (DOST-FNRI) or through actual weighing of the food samples.

2.2.2. Biochemical. Blood samples were obtained in the morning $(0600 \mathrm{H}$ to $0900 \mathrm{H})$ via venipuncture. Precautions were considered throughout the procedure to minimize exposure of samples to air and light. Approximately, $10^{\circ} \mathrm{mL}$ venous blood samples to accommodate all the biomarkers needed for the survey was extracted using a sterile syringe and transferred to a blue top tube. After a marked separation of serum and red cell was seen, the tube was centrifuged for 10 minutes. Serum was pipetted into microcentrifuge tubes. All serum were kept in freezers or in ice chests with dry ice. Frozen blood samples were transported to the Biochemical Laboratory $(\mathrm{BL})$ of DOST-FNRI where these were stored in freezers at $-80^{\circ} \mathrm{C}$ until analysis.

The best indicator of vitamin $\mathrm{D}$ status is the serum 25hydroxyvitamin D (25(OH)D) concentration [10]. Total serum 25-hydroxyvitamin D ((25-OH(D)) was analyzed using the electrochemiluminescence binding assay (ECLIA) 
method in a selected ISO 15189 accredited laboratory in Metro Manila. The cutoffs for vitamin D levels are deficient $(<50 \mathrm{nmol} / \mathrm{L})$, insufficient $(51-74 \mathrm{nmol} / \mathrm{L})$, and sufficient $(\geq 75 \mathrm{nmol} / \mathrm{L})[2,11]$.

2.3. Data Processing. Food records were encoded, and estimated vitamin D intakes were processed with a computer system called the Individual Dietary Evaluation System. This system contains the data of an updated Filipino Food Composition Table (FCT) created and used in previously published studies. The updated FCT contains 27 nutrients from 1359 foods. About half of the data (47\%) were from the United Sates Department of Agriculture (USDA) national nutrient database, and $39 \%$ of the data were from the original Filipino FCT compiled by the FNRI [12]. The rest of the data were sourced from the food composition database of Association of Southeast Asian Nations and other Asian countries such as Japan (8\%) and information from food labels (6\%). All imported data were adapted according to the International Network of Food Data Systems guidelines Food Agriculture Organization [13].

Quality control of the dietary intake data was conducted in two steps. In the first step, the foods reported by a participant were reviewed and information including coding and quantity reported were screened and validated. In the second step, vitamin D intakes were reviewed to identify implausible values by using the method described by LopezOlmedo et al. [14]. For implausible micronutrient intakes, excessive intakes were defined as those that exceeded 1.5 times the 99th percentile of the observed intake distribution of the nutrient in the corresponding sex and age group. Intakes above the upper limit were substituted by a random value generated from a uniform distribution in the intervals with the lower bound equal to the 95th percentile of the observed intake and an upper bound equal to 1.5 times the 99th percentile [14].

To investigate food groups consumed and food sources of vitamin D, a list of 80 food groups was used in a similar format from previous dietary intake studies in young children [15] (Table 1). Data analyses for food groups consumed and sources of vitamin D intake were based on the first 24-h dietary recall. All foods and beverages reported were assigned to one of the 80 food groups.

2.4. Statistical Analysis. The Software of Intake Distribution Estimation (PC-SIDE) was used to estimate the distribution usual energy and nutrient intakes and prevalence of inadequate intake. The PC-SIDE software follows the Iowa State University (ISU) method which adjusted the daily intake to remove the effect of within-person variability, so that the estimated distribution has a variance that reflects only between-person variability. Evaluations of vitamin D were assessed against the Adequate Intake (AI) by comparing results to the Philippine Dietary Reference Intake [16].

Food group consumption (i.e., percent consuming) was expressed as the percentage of children/mothers who consumed specific food groups, at least, once on the first 24-h dietary recall regardless of the amount consumed. This method has been used in our previous studies. The weighted percentage contribution of each food group for selected key nutrients was calculated by adding the amount of a given nutrient provided by each food group for all individuals and dividing by the total intake of that nutrient consumed by all individuals from all foods and beverages.

Stata (Stata Statistical Software, release 15, Stata Copr. 2017) was used to calculate the contribution of each food group to the total vitamin $\mathrm{D}$ intake. Independent $t$-test was used to test the difference of mean vitamin $\mathrm{D}$ intake for two groups. One-way ANOVA with Bonferroni multiple comparison adjustment was used to test the difference of mean vitamin $\mathrm{D}$ intake for more than two groups. The chi-square test was conducted to test the association between vitamin D and the characteristic of the population.

\section{Results}

Table 2 presents the characteristic of subjects and the distribution of usual vitamin $\mathrm{D}$ intake. The average age of 6-12years-olds is 9.4 years. For boys, their average age is 9.5 years, and for girls, it is 9.4 years. There is a similar percentage of boys and girls in the study. Sixty-four percent of the children were from rural areas. About $17 \%, 20 \%, 31 \%$, and $32 \%$ of the children were from NCR, Luzon, Visayas, and Mindanao, respectively. Approximately one quarter (26\%) of the participants were classified as rich, while the other $36 \%$ and $38 \%$ were classified as middle and poor, respectively. Twenty-five percent $(25 \%)$ of the participants were stunted.

The average vitamin D intake was $2.0 \mathrm{mg} / \mathrm{d}$. Girls have slightly higher intake of vitamin D compared to boys. Children from rural areas have significantly higher intake of vitamin $\mathrm{D}$ than those from urban areas. Children from Luzon have significantly higher intake compared to those from the other islands. Children from wealthy family have significantly higher consumption of vitamin D. Stunted children have significantly lower intake of vitamin D compared to those who are not (Table 2).

In Table 3, children's vitamin D intake was categorized into 5 groups (Q1, Q2, Q3, Q4, and Q5). Each group represents $20 \%$ of the total sample. The chi-square test showed that urbanity, island group, wealth status, and stunting were significantly associated to vitamin D quintiles.

Table 4 presents the distribution of serum concentration of $25(\mathrm{OH}) \mathrm{D}$ of $6-12$-year-old children. The average serum concentration of $25(\mathrm{OH}) \mathrm{D}$ was $72.7 \mathrm{nmol} / \mathrm{L}$. Boys have higher vitamin D level than girls. Children from rural areas have higher vitamin D level compared to those from urban areas. Children from NCR have the lowest vitamin D level compared to those from other areas. About $60.6 \%$ have deficient and insufficient of vitamin D concentration. Sex, urbanity, island, and stunting status were associated to vitamin D status (Table 5).

3.1. Food Sources of Children in Vitamin D Nutrient. The top 5 commonly consumed foods of children aged 6-12 years were rice $(97 \%)$, fish $(54 \%)$, vegetables (50\%), eggs (34\%), 
TABLE 1: Food group classification.

\begin{tabular}{|c|c|c|}
\hline 1. MILK & 28. VEGETABLES & SWEETS and SNACKS \\
\hline 2. Infant Formula & 29. Dark green-leafy vegetables & 55. SWEET BAKERY PRODUCTS \\
\hline 3. Toddler/Preschooler Formula & 30. New Zealand spinach lvs & 56. Cookies \\
\hline 4. Milk (fluid And powdered ) & 31. Broccoli & 57. Biscuits/crackers \\
\hline 5. Cheese & 32. Cabbage, green & 58. Sweet breads \\
\hline 6. Yoghurt & 33. Other local leafy, petioles, and salad vegetables & 59. Cakes \\
\hline $\begin{array}{l}\text { MEAT/POULTRY/FISH/ } \\
\text { BEANS }\end{array}$ & 34. Deep yellow vegetables & 60. Ice cream and popsicles \\
\hline 7. Beef & 35. Carrot & 61. Candy \\
\hline 8. Carabeef & 36. Sweet potato, yellow & 62. Sugar \\
\hline 9. Pork & 37. Cassava, yellow & 63. Syrup \\
\hline 10. Goat/lamb & 38. Squash fruit & 64. Preserves, jams, and jellies \\
\hline 11. Chicken & 39. Squash, summer fruit & 65. Native snacks \\
\hline 12. Duck & 40. Root and tuberous vegetable & 66. Savoury snacks \\
\hline 13. Sausages/luncheon meat & 41. Sweet potato & SWEETENED BEVERAGES \\
\hline 14. Luncheon meat & 42. Potato & 67. Fruit-based beverages \\
\hline 15. Cold cuts (ham) & 43. Other vegetables & 68. Concentrated fruit juice drinks \\
\hline 16. Fish & FRUITS and $100 \%$ FRUIT JUICE & $\begin{array}{l}\text { 69. Powdered fruit juice drinks/fruit-flavored } \\
\text { drinks }\end{array}$ \\
\hline 17. Eggs and egg dishes & 44. Fruit, fresh & 70. Ready-to-drink fruit juice drinks \\
\hline 18. Beans, nuts, and peas & 45. Apples & 71. Soft drinks (Coco Cola) \\
\hline $\begin{array}{l}\text { GRAINS AND GRAIN } \\
\text { PRODUCTS }\end{array}$ & 46. Avocado & $\begin{array}{l}\text { 72. Chocolate beverages/chocolate-flavored } \\
\text { beverages }\end{array}$ \\
\hline 19. Cereal & 47. Banana & 73. Other sweetened beverages \\
\hline 20. Bread & 48. Mango & 74. All mixed dishes \\
\hline 21. Crackers & 49. Melon & 75. Meat-based mixed dishes \\
\hline $\begin{array}{l}\text { 22. Pancakes, waffles, and french } \\
\text { toast }\end{array}$ & 50. Citrus fruits & 76. Nut/pea/bean-based mixed dishes \\
\hline 23. Rice & 51. Cherries and berries & 77. Grain-based mixed dishes \\
\hline 24. Pasta & 52. Papaya & 78. Soups \\
\hline 25. Noodles & 53. Food fruit, canned & OTHER \\
\hline 26. Corn grits & $\begin{array}{l}54.100 \% \text { fruit JUICE (lemon, mango, apple, and } \\
\text { pineapple) }\end{array}$ & 79. Fats and Oils \\
\hline 27. Cornmeal & & $\begin{array}{l}\text { 80. Condiments, sauces, herbs, spices, and other } \\
\text { seasonings }\end{array}$ \\
\hline
\end{tabular}

TABLe 2: Descriptive analysis and usual vitamin D intake of children.

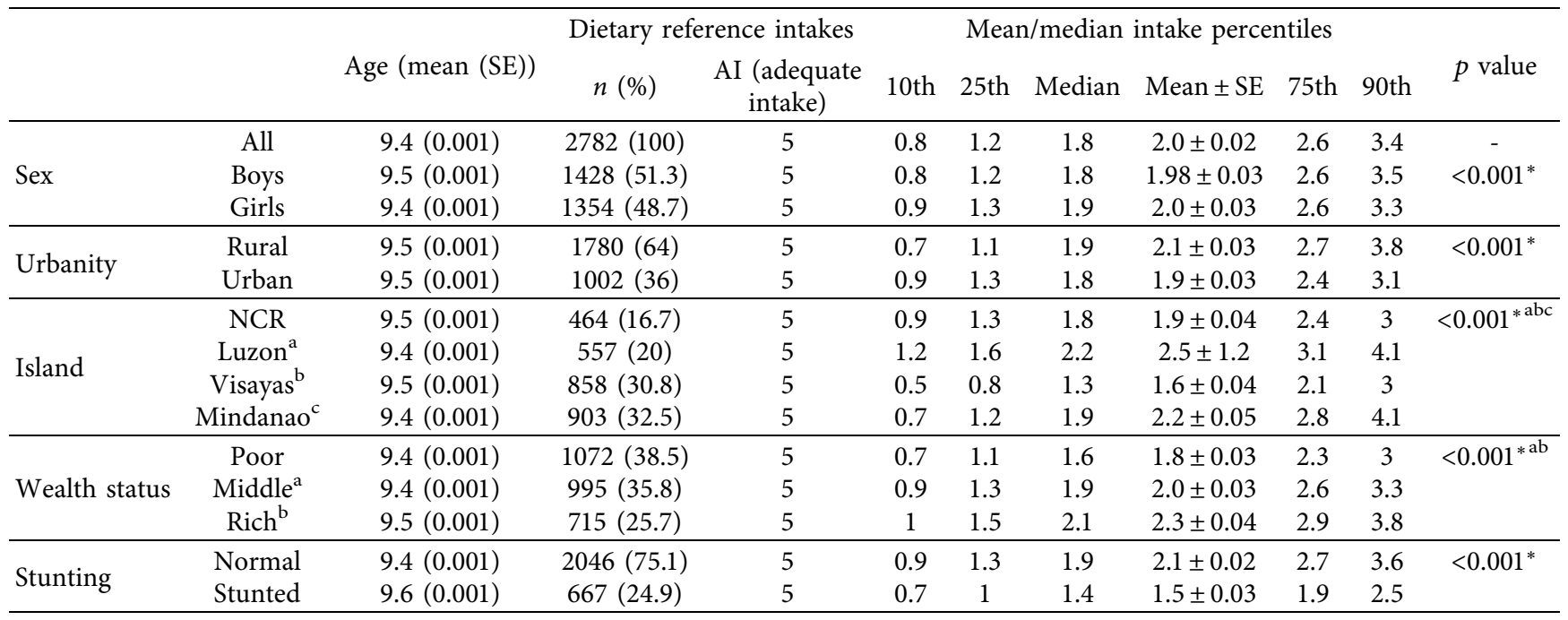

\footnotetext{
${ }^{*}$ Significant at $\alpha=0.05$ ( $t$-test and ANOVA); NS- not significant.
} 
Table 3: Usual vitamin D intake level by sex, urbanity, island group, wealth status, and stunting.

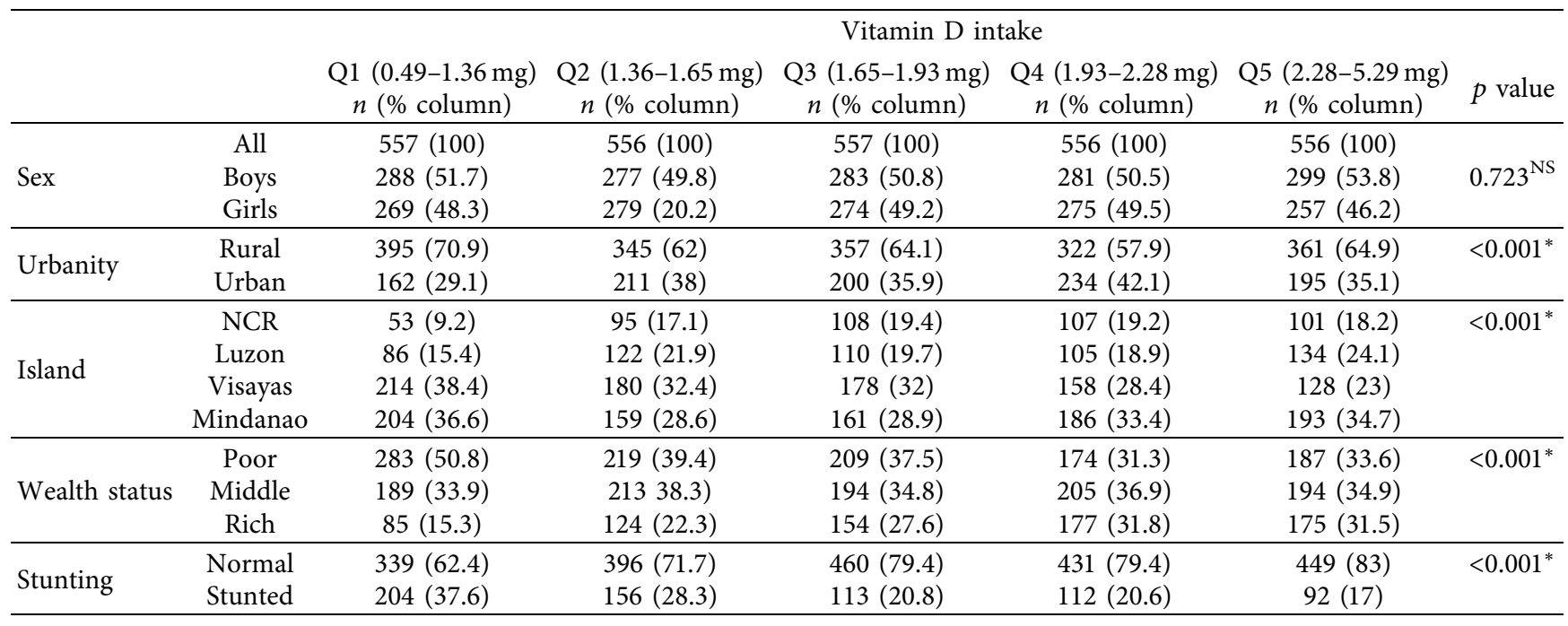

${ }^{*}$ Significant at $\alpha=0.05$ (chi-square); NS- not significant.

TABle 4: Distribution of vitamin D serum level concentration of children.

\begin{tabular}{|c|c|c|c|c|c|c|c|c|c|}
\hline & & \multirow{2}{*}{$n(\%)$} & \multicolumn{7}{|c|}{ Distribution of serum concentration of $25(\mathrm{OH}) \mathrm{D}$} \\
\hline & & & 10th & 25 th & Median & Mean \pm SE & 75th & 90th & $p$ value \\
\hline \multirow{3}{*}{ Sex } & All & 789 (100) & 50.6 & 59.5 & 71 & $72.7 \pm 0.67$ & 84 & 98.8 & - \\
\hline & Boys & $395(50.1)$ & 52 & 61.6 & 73.9 & $76.6 \pm 1$ & 90.3 & 105.4 & $<0.001^{*}$ \\
\hline & Girls & $394(49.9)$ & 49.2 & 57.3 & 67.4 & $68.8 \pm 0.8$ & 78.1 & 91 & \\
\hline \multirow{2}{*}{ Urbanity } & Rural & $493(62.7)$ & 54.3 & 63.4 & 74.4 & $76.9 \pm 0.8$ & 88.4 & 103.3 & $<0.001^{*}$ \\
\hline & Urban & $296(37.3)$ & 46.3 & 54.8 & 65 & $64.8 \pm 1$ & 73.9 & 90.3 & \\
\hline \multirow{4}{*}{ Island } & NCR & $133(16.8)$ & 42.5 & 49.4 & 56.4 & $58.4 \pm 1.3$ & 67.5 & 76.2 & $<0.001^{* a b c}$ \\
\hline & Luzon $^{\mathrm{a}}$ & $168(21.2)$ & 54.1 & 63 & 73.3 & $75.8 \pm 1.3$ & 85.5 & 100.8 & \\
\hline & Visayas $^{\mathrm{b}}$ & $200(25.2)$ & 52.8 & 61.2 & 73.5 & $76.6 \pm 1.4$ & 89.6 & 105.5 & \\
\hline & Mindanao $^{c}$ & $292(36.8)$ & 54.9 & 62.7 & 72.6 & $74.9 \pm 1$ & 85.1 & 94.5 & \\
\hline \multirow{3}{*}{ Wealth tertiles } & Poor & $324(41.2)$ & 52.3 & 60.5 & 71.7 & $73 \pm 1$ & 82.8 & 97.4 & $0.200^{\mathrm{NS}}$ \\
\hline & Middle $^{a}$ & $300(37.8)$ & 51.6 & 59.1 & 70.2 & $73.6 \pm 1.1$ & 86.3 & 100.9 & \\
\hline & Rich $^{\mathrm{b}}$ & $165(20.9)$ & 48.9 & 56.7 & 67.5 & $70.5 \pm 1.5$ & 83.2 & 97.2 & \\
\hline \multirow{2}{*}{ Stunting } & Normal & $584(74.9)$ & 49.1 & 58.2 & 70 & $71.7 \pm 0.8$ & 83.3 & 97.4 & $0.056^{\mathrm{NS}}$ \\
\hline & Stunted & $196(25.1)$ & 55.6 & 63.3 & 73.4 & $75.9 \pm 1.2$ & 87.7 & 99.7 & \\
\hline
\end{tabular}

*Significant at $\alpha=0.05$ ( $t$-test and ANOVA); NS- not significant.

TABLE 5: Vitamin D serum level status of children.

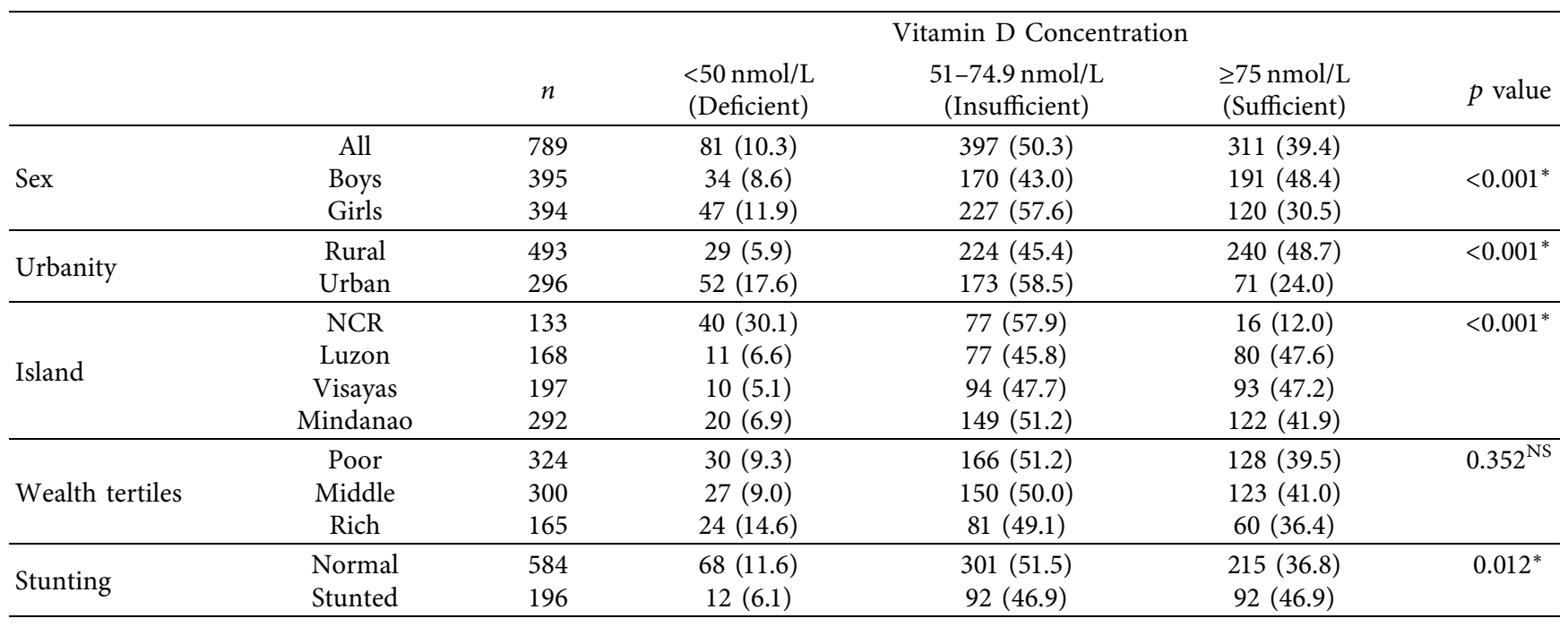

* Significant at $\alpha=0.05$ (chi-square test). 


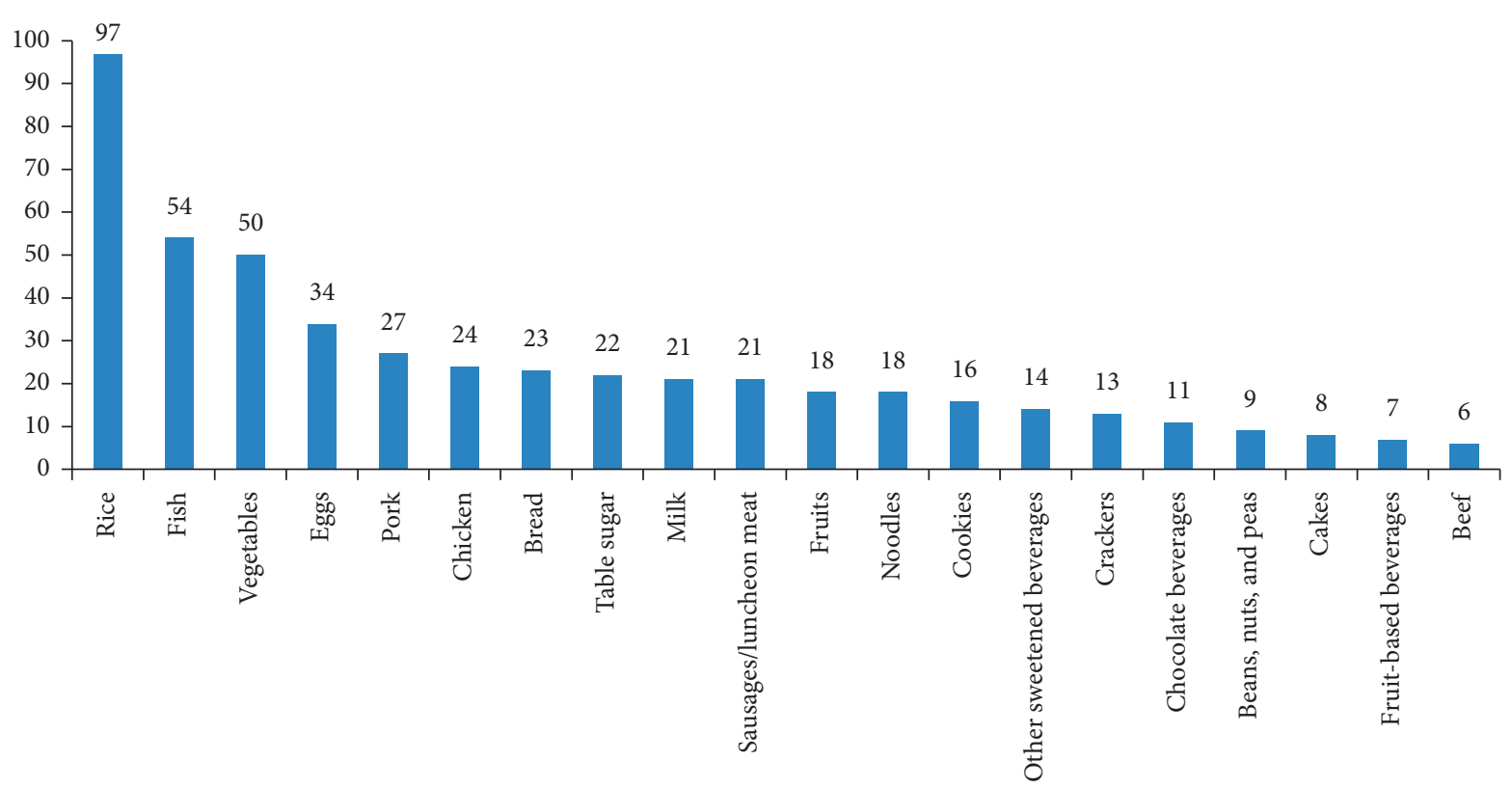

FIgURE 1: Most commonly consumed foods of children aged 6-12 years.

and pork (27\%) (Figure 1). The top five highest contributors to vitamin $\mathrm{D}$ were fish, being the highest contributor $(53 \%)$, pork (19\%), eggs (16\%), sausages/luncheon meat $(5 \%)$, and chocolate beverages (3\%). Analyzing the data by island groups, fish contributed $62-64 \%$ of vitamin D intake in Visayas and Mindanao (Table 6). Although fish is also the top contributor of vitamin D in NCR and Luzon; it only contributed about $31 \%$ and $44 \%$, respectively. Also, pork contributed quite high amounts of vitamin D in NCR (31\%) and Luzon (25\%).

\section{Discussion}

This study was conducted primarily to analyze the status of vitamin $D$, usual intake, and its food sources among children aged 6-12 years who participated in the 2018 NNS conducted by the Department of Science and Technology-Food and Nutrition Research Institute (DOST-FNRI). Only 8 randomly and geographically selected areas in NCR, Luzon, Visayas, and Mindanao were considered in this analysis.

The sun is the best source of vitamin $\mathrm{D}$; hence, nonexposure to sunlight leads to decreased vitamin D synthesis. The Philippines has plenty of sunlight, but vitamin D deficiency (10.3\%) and insufficiency $(50.3 \%)$ is very high among the 6-12-year-old children. However, our result is lower than the prevalence in Indonesia among children aged 7-12 years, wherein the prevalence of vitamin D deficiency was $15 \%$ and insufficiency was $75.8 \%$ [17]; also, a higher prevalence of vitamin D deficiency $(59.1 \%)$ among schoolchildren in Busan was reported [18].

The National Capital Region has the highest prevalence of deficiency (30.1\%) and insufficiency (57.9\%) which is significantly higher than that of the three island groups. A similar result was found in our previous study of vitamin D deficiency among adults in the Philippines. NCR has the
TABle 6: Food sources of total vitamin D by island groups $(n=2728)$.

\begin{tabular}{lccccc}
\hline & $\begin{array}{c}\text { All } \\
(\%)\end{array}$ & $\begin{array}{c}\text { NCR } \\
(\%)\end{array}$ & $\begin{array}{c}\text { Luzon } \\
(\%)\end{array}$ & $\begin{array}{c}\text { Visayas } \\
(\%)\end{array}$ & $\begin{array}{c}\text { Mindanao } \\
(\%)\end{array}$ \\
\hline Fish & 53 & 31 & 44 & 62 & 64 \\
Pork & 19 & 31 & 25 & 10 & 15 \\
Eggs & 16 & 21 & 14 & 16 & 14 \\
Sausages/luncheon & 5 & 6 & 6 & 5 & 2 \\
meat & 3 & 3 & 4 & 4 & 3 \\
Chocolate beverages & 1 & 2 & 2 & 1 & 1 \\
Chicken & 1 & 3 & 1 & - & 0 \\
Milk & 1 & 1 & 1 & 1 & 0 \\
Cereals & 1 & - & 1 & 0 & 1 \\
Noodles & 0 & 1 & 1 & 1 & 0 \\
Cakes & - & 1 & - & - & - \\
Native desserts/snacks & - & - & 1 & 0 & - \\
Beef & 100 & 100 & 100 & 98 & 99 \\
Total & & & & & \\
\hline
\end{tabular}

highest prevalence of vitamin D insufficiency compared to Cebu (located in Visayas) and Davao (located in Mindanao) [19]. This could be attributed to differences [20]. Although our the previous study was among adults who have different body frame and biological nutrient metabolism than our study children in this present study, we believe that geographical location could be a prime factor. NCR is a highly urbanized area and is the center of commerce, employment, and education. It has limited space, so people including children tend to spend more time indoors. Furthermore, in NCR, children go to classes early in the morning at 6:00 AM and go home at around 12:00 noon. Since NCR is a metropolitan area equipped with the different gadgets and electronic devices, children tend to stay inside the house to play computer games or watch TV. Time outside home to get sunlight is very limited. In a previous study, children who watched more TV, played less outside, and used less biking 
to school were associated with higher risk of vitamin $\mathrm{D}$ deficiency [21]. This scenario may also be true in other urbanized cities or cosmopolitan areas. In has been postulated that urbanity is associated to increase in indoor lifestyles and regular use of sunscreen. This might be the reason why there is a high prevalence of vitamin $\mathrm{D}$ deficiency and insufficiency found in our children in urban areas as compared to those living in rural areas. High prevalence of vitamin $\mathrm{D}$ deficiency in the urban area was also reported in Turkey [22], and China [23]. Additionally, a communitybased study showed that the prevalence of vitamin $\mathrm{D}$ deficiency among Indians living in urban areas ranged from $50 \%$ to $94 \%$ [24].

The girls in this study have higher prevalence of vitamin $\mathrm{D}$ deficiency (11.9\%) compared to boys (8.9\%) using the cutoffs for vitamin D deficiency as $<50 \mathrm{nmol} / \mathrm{L}$. In a study among children aged $6-18$ years, about $93 \%$ were vitamin $\mathrm{D}$ deficient (using cutoff value as serum 25 hydroxy D $<20 \mathrm{ng} /$ $\mathrm{ml}$ ), and the prevalence among female children was higher than that among men because most men have a higher sun exposure than females due to more outdoor lifestyle and activities as they have more freedom [25]. A high prevalence of vitamin D deficiency and insufficiency (65.1\%) among healthy adolescents in United Arab Emirates was also more common in females [26]. The main reason that a female has low vitamin D serum was the difference in the amount of subcutaneous fat between genders. Females have more subcutaneous fat than males [27]. It has been hypothesized that more amount of subcutaneous fat in females could take up more vitamin $\mathrm{D}$ particles produced from the skin that could lead to lower vitamin D particles entering in the blood circulation [28]. Moreover, lifestyle differences between females and males could give difference in vitamin $\mathrm{D}$ status. Females more often use sunscreen when they are outdoors.

The usual intake of vitamin D among Filipino children was $2.0 \mu \mathrm{g}$ per day which is below the recommended intake per day of $5 \mu \mathrm{g}$ in children (PDRI 2015). This is obviously too low to influence $25(\mathrm{OH}) \mathrm{D}$ levels of the children. The Institute of Medicine (IOM) recommends a daily intake of vitamin D of 400 international units (IU) or $10 \mu \mathrm{g}$ daily and the tolerable upper limit of $2000 \mathrm{IU}$ daily or $50 \mu \mathrm{g}$ [29]. Moreover, it has been reported that, to raise the serum $25(\mathrm{OH}) \mathrm{D}$ to over $75 \mathrm{nmol} / \mathrm{L}$, a daily intake of 1000-2000 IU is required [30]. Lack of vitamin D intake can cause softening and weakening of bones of children known as rickets due to poor mineralization and may stop them from reaching their genetically programmed height and great bone mass [31]. This might be the reason why the country is facing the problem of stunting among our children. Moreover, it has been found in a recent prospective, double-blind placebo study that vitamin D has resulted in a significant decrease (42\%) in the incidence of influenza infection [32]. This is because of the role of Vitamin D in suppressing the development of cytokine by simultaneously boosting the innate immune system to respond to the viral load immediately. Some researchers also indicated the possible involvement of vitamin D during the 1918-1919 viral influenza pandemic in suppressing cytokine storms [33]. Most importantly, vitamin D is very important in enhancing the immune response of flu and previous coronaviruses $[8,34]$ because of its ability in suppressing cytokine production [35]. It is in this notion that, during this time of the coronavirus pandemic (COVID-19), increasing vitamin D intake or exposure to sunlight could be very beneficial to squash the cytokine storm occurring during the attack of COVID-19.

Major food sources may differ in other countries. In this study the main food sources of vitamin D among children are fish (53\%), pork (19\%), and egg/egg dishes (16\%). In the United States, their main sources of vitamin D are milk, cereal, and fish [36]; in Japan and the United Kingdom, fish is their main food source of vitamin $\mathrm{D}$ which is similar to our study $[37,38]$. High consumption of fish can help increase serum concentration of $25(\mathrm{OH}) \mathrm{D}$ [39]. It has been reported that regular consumption of fish is associated with a higher vitamin D intake [40]. However the amount of intake of these vitamin D-rich foods in our children in this study is very limited (fish $(41 \mathrm{~g})$, pork (22.1 g), and eggs/egg dishes (27.7 g)).

The study is only limited to the comparison of Vitamin D serum level in Filipino schoolchildren aged 6-12 years. Variables such as duration of sun exposure and time of the day during sun exposure were not evaluated.

\section{Conclusions}

The prevalence of vitamin D insufficiency among Filipino children 6-12 years is significantly high (50.3\%). Females have a higher prevalence of vitamin $\mathrm{D}$ deficiency and insufficiency compared to the males. NCR has the highest deficiency compared to the other areas. The usual intake of vitamin $\mathrm{D}$ is only $2 \mu \mathrm{g} / \mathrm{day}$ which is far below the recommended dietary intake of $5 \mu \mathrm{g} /$ day. The main food sources of vitamin $\mathrm{D}$ in this group of children are fish, pork, and eggs/ egg dishes, but these were consumed in limited amounts. It is highly recommended to have outdoor activities and increase the vitamin $\mathrm{D}$ intake of school children to contribute to addressing stunting and improving immunity.

\section{Data Availability}

The data in this study are not available for public use because of the confidentiality agreement between the researchers and the respondents' parents as stipulated in the Ethics Protocol of Food and Nutrition Research Institute.

\section{Conflicts of Interest}

The authors declare no conflicts of interest.

\section{Acknowledgments}

The author's would like to acknowledge the field researchers and the respondents of this study. The conduct of the National Nutrition Survey was funded by the Government of the Philippines. Nestlé Philippines funded the analysis of serum vitamin $\mathrm{D}$.

\section{References}

[1] H. F. Deluca, "Overview of general physiologic features and functions of vitamin D," The American Journal of Clinical Nutrition, vol. 80, no. 6, pp. 1689S-1696S, 2004. 
[2] M. F. Holick and T. C. Chen, "Vitamin D deficiency: a worldwide problem with health consequences," The American Journal of Clinical Nutrition, vol. 87, no. 4, pp. 1080S-1086S, 2008.

[3] M. Fiscaletti, P. Stewart, and C. Munns, "The importance of vitamin D in maternal and child health: a global perspective," Public Health Reviews, vol. 38, no. 1, pp. 1-17, 2017.

[4] J. A. Weydert, "Vitamin D in children's health," Children, vol. 1, no. 2, pp. 208-226, 2014.

[5] C. Palacios and L. Gonzalez, "Is vitamin D deficiency a major global public health problem?" The Journal of Steroid Biochemistry and Molecular Biology, vol. 144, pp. 138-145, 2014.

[6] J. Hilger, A. Friedel, R. Herr et al., "A systematic review of vitamin D status in populations worldwide," British Journal of Nutrition, vol. 111, no. 1, pp. 23-45, 2014.

[7] M. Wacker and M. F. Holick, "Vitamin D-effects on skeletal and extraskeletal health and the need for supplementation,", Nutrients, vol. 5, no. 1, pp. 111-148, 2013.

[8] C. Aranow, "Vitamin D and the immune system," Journal of Investigative Medicine, vol. 59, no. 6, pp. 881-886, 2011.

[9] A. A. Ginde, J. M. Mansbach, and C. A. Camargo, "Association between serum 25-hydroxyvitamin D level and upper respiratory tract infection in the third national health and nutrition examination survey," Archives of Internal Medicine, vol. 169, no. 4, pp. 384-390, 2009.

[10] Institute of Medicine, Dietary Reference Intakes: Calcium and Vitamin D, National Academy of Sciences, Washington, DC, USA, 2011.

[11] M. F. Holick, "Vitamin D status: measurement, interpretation, and clinical application," Annals of Epidemiology, vol. 19, no. 2, pp. 73-78, 2009.

[12] Food and Nutrition Research Institute, Department of Science and Technology, The Philippine Food Composition Tables 1997, Department of Science and Technology, Food and Nutrition Research Institute, Manila, Philippines, 1997.

[13] International Network of Food Data Systems (INFOODS) Standards and Guidelines. http://www.fao.org/infoods/ infoods/standards-guidelines/en/.

[14] N. Lopez-Olmedo, do, A. L. Carriquiry, S. Rodriguez-Ramirez et al., Usual intake of added sugars and saturated fats is high while dietary fiber is low in the Mexican population," Journal of Nutrition, vol. 146, pp. 1856S-1865S, 2016, Lopez-Olme.

[15] L. Denney, I. Angeles-Agdeppa, M. V. Capanzana et al., "Nutrient intakes and food sources of Filipino infants, toddlers and young children are inadequate: findings from the national nutrition survey 2013," Nutrients, vol. 10, no. 11, 2018.

[16] Department of Science and Technology- Food and Nutrition Research Institute (DOST-FNRI), Philippine Dietary Reference Intakes 2015: Summary of Recommendation, Department of Science and Technology-Food and Nutrition Research Institute (DOST-FNRI), Manila, Philippines, 2015.

[17] F. Soesanti, A. Pulungan, B. Tridjaja et al., "Vitamin D profile in healthy children aged 7-12 years old in Indonesia," International Journal of Pediatric Endocrinology, vol. 2013, no. 1, p. P167, 2013.

[18] Y. E. Batubara, B. R. Kim, W. B. Choi et al., "Vitamin D deficiency in children aged 6 to 12 years: single center's experience in Busan," Annals of Pediatric Endocrinology \& Metabolism, vol. 21, no. 3, pp. 149-154, 2016.

[19] I. Angeles-agdeppa, L. A. Perlas, and M. V. Capanzana, "“Vitamin D status of Filipino adults : evidence from the 8th national nutrition survey 2013," Malaysian Journal of $\mathrm{Nu}$ trition, vol. 24, no. 3, pp. 395-406, 2018.
[20] S. Bindusha, I. Riaz, K. R. Sujith, and L. Kailas, "The vitamin D status in 6-14 Year old children attending tertiary care teaching hospital in south India," International Journal of Current Research and Review, vol. 9, no. 11, pp. 5-10, 2017.

[21] T. Voortman, E. H. Van Den Hooven, A. C. Heijboer, A. Hofman, V. W. Jaddoe, and O. H. Franco, "Vitamin D deficiency in school-age children is associated with sociodemographic and lifestyle factors," The Journal of Nutrition, vol. 145, no. 4, p. 791, on, 2015.

[22] G. Karagüzel, B. Dilber, G. Çan, A. Ökten, O. Değer, and M. F. Holick, "Seasonal vitamin d status of healthy schoolchildren and predictors of low vitamin D status," Journal of Pediatric Gastroenterology and Nutrition, vol. 58, no. 5, pp. 654-660, 2014.

[23] P. Li, Y. Tian, Y. Wang et al., "The prevalence of vitamin D deficiency among schoolchildren: a cohort study from Xinxiang, China,", Journal of Pediatric Endocrinology, vol. 28, no. 5-6, pp. 629-633, 2015.

[24] P. Aparna, S. Muthathal, B. Nongkynrih et al., "Vitamin D deficiency in India," Journal of Family Medicine and Primary Care, vol. 7, pp. 324-330, 2018.

[25] U. Kapil, R. Pandey, R. Goswami et al., "Prevalence of Vitamin $\mathrm{D}$ deficiency and associated risk factors among children residing at high altitude in Shimla district, Himachal Pradesh, India," Indian Journal of Endocrinology and Metabolism, vol. 21, no. 1, pp. 178-183, 2017.

[26] S. J. Muhairi, A. E. Mehairi, A. A. Khouri et al., "Vitamin D deficiency among healthy adolescents in Al Ain, United Arab Emirates," BMC Public Health, vol. 13, no. 1, 2013.

[27] X. Yan, N. Zhang, S. Cheng, Z. Wang, and Y. Qin, "Gender differences in Vitamin D status in China," Medical Science Monitor, vol. 25, pp. 7094-7099, 2019.

[28] B. H. Wang, J. Zargooshi, A. D. Berger et al., "Gender differences in subcutaneous and perirenal fat distribution," Surgical and Radiologic Anatomy, vol. 32, no. 9, pp. 879-882, 2010.

[29] Institute of Medicine, Food and Nutrition Board, Dietary Reference Intakes for Calcium and Vitamin D, National Academy Press, Washington, DC, USA, 2010.

[30] C. Michie and S. Bangalore, "Managing vitamin D deficiency in children," London Journal of Primary Care, vol. 3, no. 1, pp. 31-36, 2010.

[31] M. F. Holick, "Sunlight and vitamin D for bone health and prevention of autoimmune diseases, cancers, and cardiovascular disease," The American Journal of Clinical Nutrition, vol. 80, no. 6, pp. 1678S-1688S, 2004.

[32] M. Urashima, T. Segawa, M. Okazaki, M. Kurihara, Y. Wada, and H. Ida, "Randomized trial of vitamin D supplementation to prevent seasonal influenza A in schoolchildren," The American Journal of Clinical Nutrition, vol. 91, no. 5, pp. 1255-1260, 2010.

[33] W. B. Grant and E. Giovannucci, "The possible roles of solar ultraviolet- $\mathrm{B}$ radiation and Vitamin $\mathrm{D}$ in reducing case-fatality rates from the 1918-1919 influenza pandemic in the United States," Dermato-Endocrinology, vol. 1, no. 4, pp. 215-219, 2009.

[34] N. Goncalves-Mendes, J. Talvas, C. Dualé et al., "Impact of vitamin $\mathrm{D}$ supplementation on influenza vaccine response and immune functions in deficient elderly persons: a randomized placebo-controlled trial," Frontiers in Immunology, vol. 10, 2019.

[35] E. Parlak, A. Ertürk, Y. Çağ et al., "The effect of inflammatory cytokines and the level of vitamin D on prognosis in Crimean-Congo hemorrhagic fever," International Journal 
of Clinical and Experimental Medicine, vol. 8, no. 10, pp. 18302-18310, 2015.

[36] K. M. Hill, S. S. Jonnalagadda, A. M. Albertson, N. A. Joshi, and C. M. Weaver, "Top food sources contributing to vitamin $\mathrm{D}$ intake and the association of ready-to-eat cereal and breakfast consumption habits to vitamin D intake in Canadians and United States Americans," Journal of Food Science, vol. 77, no. 8, pp. H170-H175, 2012.

[37] L. Henderson, K. Irving, J. Gregory et al., The National Diet and Nutrition Survey: Adults Aged 19 to 64 Years Vitamin and Mineral Intake and Urinary Analytes, TSO, London, UK, 2003.

[38] K. Nakamura, M. Nashimoto, Y. Hori, and M. Yamamoto, "Serum 25-hydroxyvitamin D concentrations and related dietary factors in peri- and postmenopausal Japanese women," The American Journal of Clinical Nutrition, vol. 71, no. 5, pp. 1161-1165, 2000.

[39] K. Nakamura, "Vitamin D insufficient in Japanese populations: from the viewpoint of the prevention of osteoporosis," Journal of Bone and Mineral Metabolism, vol. 24, no. 1, pp. 1-6, 2006.

[40] A. Jungert, A. Spinneker, A. Nagel et al., "Dietary intake and main food sources of vitamin D as a function of age, sex, vitamin D status, body composition, and income in an elderly German cohort," Food \& Nutrition, vol. 1, pp. 1-8, 2014. 